\title{
Erratum to: Ambulatory activity in incident Parkinson's: more than meets the eye?
}

\author{
Sue Lord · Alan Godfrey • Brook Galna • \\ Dadirayi Mhiripiri · David Burn · Lynn Rochester
}

Published online: 29 October 2013

(C) Springer-Verlag Berlin Heidelberg 2013

\section{Erratum to: J Neurol}

\section{DOI 10.1007/s00415-013-7037-5}

In the online version of the original article, Fig. 2 was incorrect. The correct version is given below.
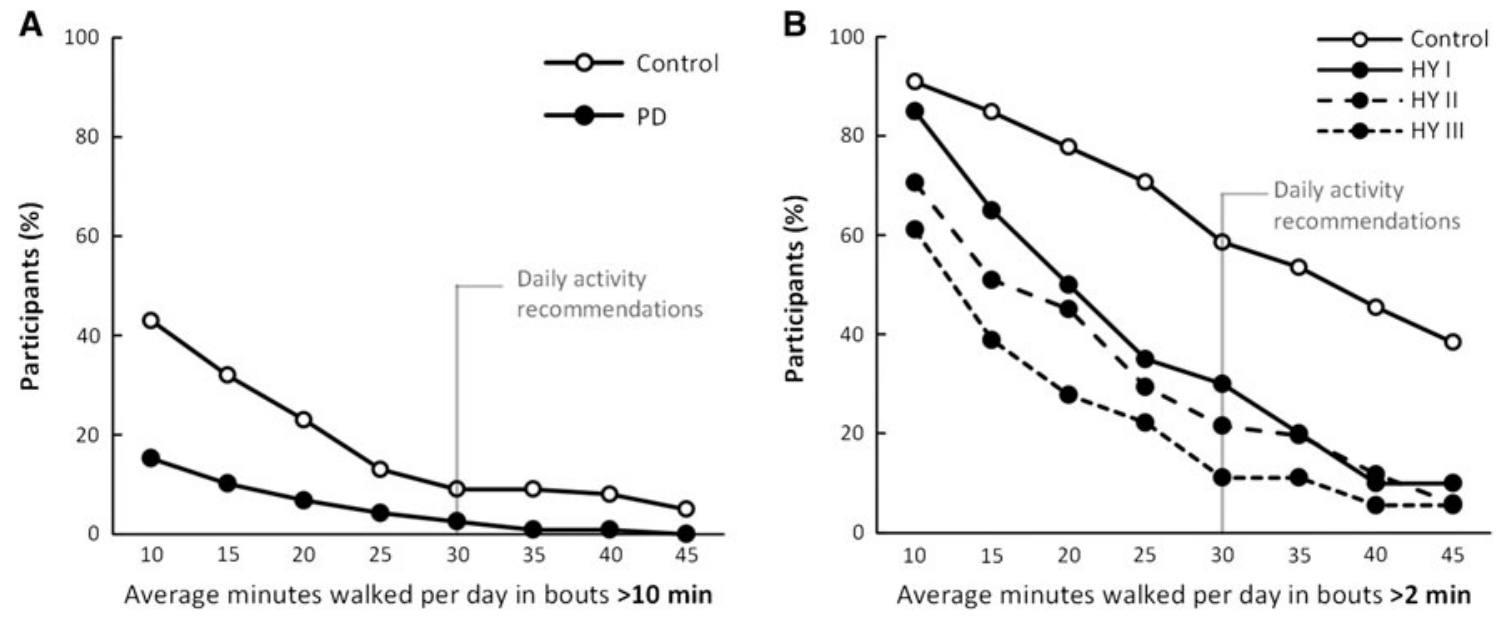

Fig. 2 Attainment of 30 min of daily activity comprised of a 10 min bouts for PD and controls; and $\mathbf{b} 2$ min bouts for controls and H\&Y groups

The online version of the original article can be found under doi:10.1007/s00415-013-7037-5.

S. Lord · A. Godfrey · B. Galna · D. Mhiripiri · D. Burn

L. Rochester $(\square)$

Clinical Ageing Research Unit, Institute for Ageing and Health,

Newcastle University, Campus for Ageing and Vitality,

Newcastle upon Tyne NE4 5PL, UK

e-mail: lynn.rochester@ncl.ac.uk 